\title{
Esthesioneuroblastoma in Young Boy: Masquerading as Invasive Aspergillosis
}

\author{
Jaimanti Bakshi, Anil K Dash, Bhumika Gupta, Naresh K Panda
}

\section{ABSTRACT}

We present the case of a 15-year-old boy with a swelling and pain in right eye. He was diagnosed as esthesioneuroblastoma on the basis of radiology and histopathology.

Keywords: Small round cell tumor, Esthesioneuroblastoma, Proptosis.

How to cite this article: Bakshi J, Dash AK, Gupta B, Panda NK. Esthesioneuroblastoma in Young Boy: Masquerading as Invasive Aspergillosis. Clin Rhinol An Int J 2013;6(3):118-120.

\section{Source of support: Nil}

Conflict of interest: None declared

\section{INTRODUCTION}

Esthesioneuroblastoma (ENB), also known as olfactory neuroblastoma, is a rare neoplasm originating from olfactory neuroepithelium. Approximately 1,000 cases have been identified since Berger and Luc described the first case in 1924. Due to the rare and complex nature of ENB, multiple opinions exist regarding the etiology, optimal staging system, and treatment modalities. These tumors often display varying biologic activity ranging from indolent growth, with patient survival exceeding 20 years, to a highly aggressive neoplasm capable of rapid widespread metastasis, with survival limited to a few months. ${ }^{1}$

\section{CASE REPORT}

A 15-year-old boy presented with protrusion of right eye of 1 month duration and patient underwent endoscopic clearance from ethmoids under general anesthesia (Fig. 1).

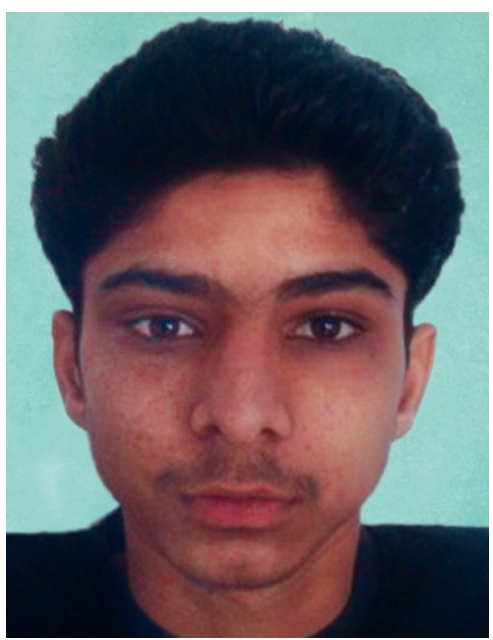

Fig. 1: Patient with right proptosis
The biopsy report came out to be invasive aspergillosis. The fungal smear was negative. The patient was given oral voriconazol for 4 months. As the proptosis did not regress after medical treatment for 4 months, external ethmoidectomy was done under general anesthesia. There was a whitish grey mass in anterior ethmoid and frontal sinus, which was observed intraoperatively. The orbital periosteum was intact. The biopsy report came out to be small round cell tumor, suggestive of esthesionuroblastoma. Further immuostaining could not be done as patient was too young, in view of delaying management. The CT scan and MRI scan was done for this patient to note the extent of disease preoperatively. NCCT PNS and orbit showed heterogeneous extracranial soft tissue in right orbit and right ethmoid sinus with erosion of surrounding bone, intracranial extension and extraocular muscles involving medial and inferior rectus muscles (Figs 2 and 3). After biopsy report this patient was managed by chemotherapy and radiotherapy. Six months post-treatment patient is doing well without any local recurrence.

\section{DISCUSSION}

The diagnosis of esthesioneuroblastoma is based on radiology and histopathology. The radiological investigation includes CT scan and MRI. The characteristic MRI finding is the presence of cyst at brain-tumor interface. Using MRI, ENB appears as hypointense to gray matter on T1-weighted images and isointense or hyperintense to gray matter on T2-weighted images. ${ }^{2}$

Esthesioneuroblastomas (ENBs) can display various histologic presentations. The hallmark of well-differentiated ENBs is arrangements of cells into rosettes or pseudorosettes (sheets and clusters). True rosettes (Flexner-Wintersteiner rosettes) refer to a ring of columnar cells circumscribing a central oval-to-round space, which appears clear on traditional pathologic sections. Pseudorosettes (HomerWright rosettes) are characterized by a looser arrangement and the presence of fibrillary material within the lumen. ${ }^{3}$

Due to the rarity and complexity of esthesioneuroblastoma (ENB), there exists considerable heterogeneity in treatment. Complete surgical resection of the tumor followed by radiation therapy is recognized by most studies as the optimal treatment. However, some institutions report success with alternative treatment sequences, including surgery without radiation. More recently, chemotherapy has been introduced 

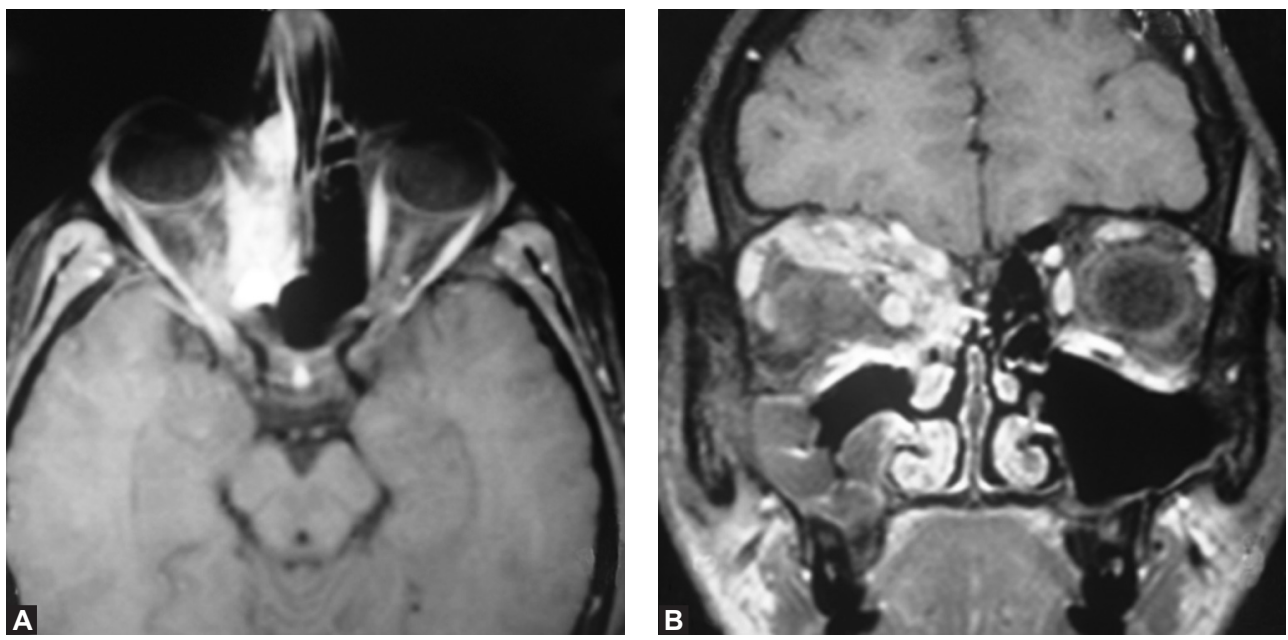

Figs 2A and B: T1 weighted MRI images (axial and coronal) showing right medial and inferior rectus involvement
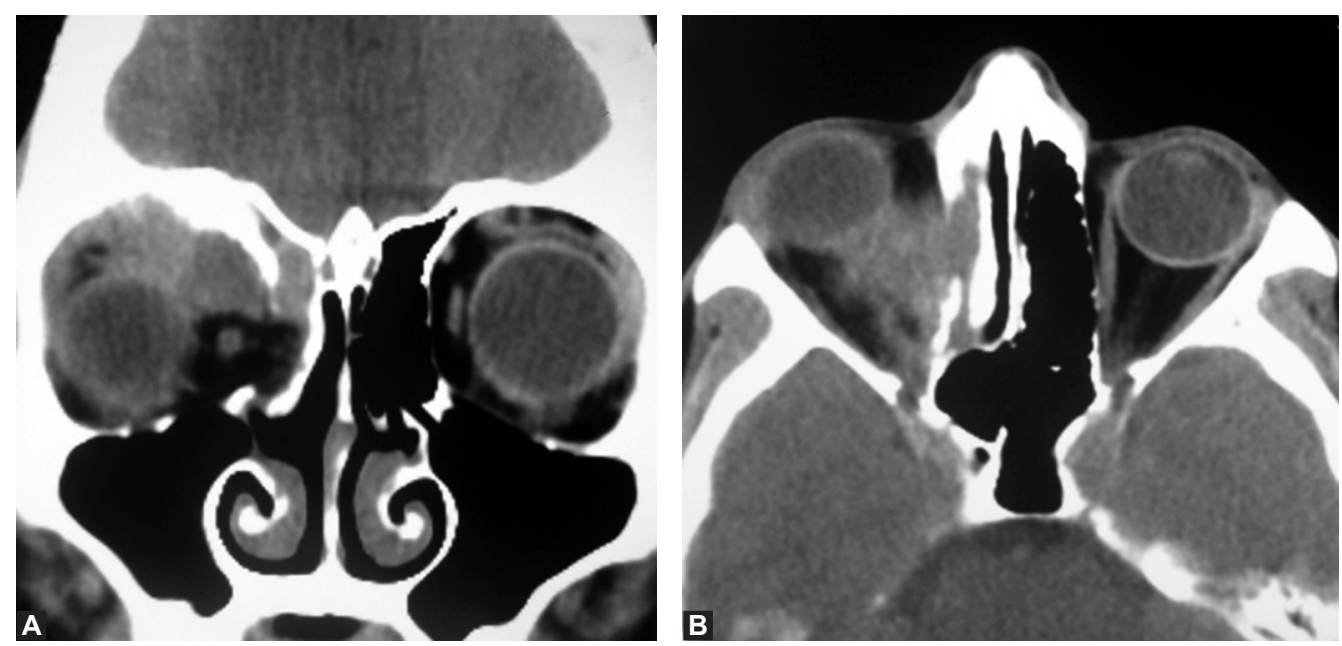

Figs 3A and B: NCCT PNS depicting intraorbital disease

in the therapeutic armamentarium. The literature gives little support to single-modality treatments; few studies advocate either surgery or radiation alone. Dulguerov's 2001 metaanalysis clearly showed lower recurrence rates for the combination of surgery and radiotherapy. ${ }^{4}$

Most institutions favor surgery as the first treatment modality, followed by postoperative irradiation. Preoperative radiation results in the usual loss of definable tumor borders, which makes an en-bloc resection problematic. However, it has been noted that a theoretical advantage to preoperative radiation therapy is to convert an inoperable tumor to one that is amenable to resection. This theory is not widely supported.

Standard techniques include external megavoltage beam and a 3-field technique; an anterior port is combined with wedged lateral fields to provide a homogeneous dose distribution. The radiation portals are nowadays planned by integrating pretreatment CT or MRI imaging within the radiotherapy software. The dose varies from 5500 to $6500 \mathrm{cGy}$. The majority of patients receive $<6000 \mathrm{cGy}$.
These doses are close to or do not exceed the maximum radiation dose recommended for sensitive structures, such as the optic nerve, optic chiasma, brainstem, retina and lens. Therefore, these patients are susceptible to cataract and glaucoma formation. A possible role of proton beam radiotherapy, intensity-modulated radiotherapy, and stereotactic radiation has been suggested. Several institutions have reported that intensity-modulated radiotherapy can provide good tumor control with low rates of radiationinduced toxicity, in children as well as in adults. There are case reports describing the use of CT-guided interstitial high-dose-rate brachytherapy. However, prospective clinical trials confirming the efficacy of these modalities have not yet been completed. ${ }^{5-9}$

The use of chemotherapy has been advocated by authors from the University of Virginia In their protocol, patients with advanced disease (e.g. Kadish stage C) are treated first with 2 cycles of cyclophosphamide $\left(300-650 \mathrm{mg} / \mathrm{m}^{2}\right)$ and vincristine (1-2 mg) with or without doxorubicin, followed 
by 50 Gy of radiotherapy, which then is followed by a craniofacial resection. With this regimen, the 5-year and 10 -year actuarial survival rates are 72 and $60 \%$ respectively. Similar results have been obtained without chemotherapy, and how much chemotherapy contributed to the cure rates is unclear. ${ }^{10}$

\section{REFERENCES}

1. Broich G, Pagliari A, Ottaviani F. Esthesioneuroblastoma: a general review of the cases published since the discovery of the tumour in 1924. Anticancer Res 1997 Jul-Aug;17(4A):2683-2706.

2. Tseng J, Michel MA, Loehrl TA. Peripheral cysts: a distinguishing feature of esthesioneuroblastoma with intracranial extension. Ear Nose Throat J 2009 Jun;88(6):E14.

3. Min KW. Usefulness of electron microscopy in the diagnosis of "small" round cell tumors of the sinonasal region. Ultrastruct Pathol 1995 Sep-Oct;19(5):347-363.

4. Dulguerov P, Allal AS, Calcaterra TC. Esthesioneuroblastoma: a meta-analysis and review. Lancet Oncol 2001 Nov;2(11): 683-690.

5. Fitzek MM, Thornton AF, Varvares M. Neuroendocrine tumors of the sinonasal tract. Results of a prospective study incorporating chemotherapy, surgery, and combined protonphoton radiotherapy. Cancer 2002 May 15;94(10):2623-2634.

6. Nichols AC, Chan AW, Curry WT, Barker FG, Deschler DG, Lin DT. Esthesioneuroblastoma: the massachusetts eye and ear infirmary and massachusetts general hospital experience with craniofacial resection, proton beam radiation, and chemotherapy. Skull Base 2008 Sep;18(5):327-337.

7. Madani I, Bonte K, Vakaet L, Boterberg T, De Neve $\mathrm{W}$. Intensity-modulated radiotherapy for sinonasal tumors: Ghent University Hospital update. Int J Radiat Oncol Biol Phys 2009 Feb 1;73(2):424-432.
8. Sterzing F, Stoiber EM, Nill S, Bauer H, Huber P, Debus J, et al. Intensity modulated radiotherapy (IMRT) in the treatment of children and adolescents - a single institution's experience and a review of the literature. Radiat Oncol 2009 Sep 23;4(1):37.

9. Tselis N,HeydR, BaghiM,Zamboglou N. Interstitial high-dose-rate, brachytheapy in advanced esthesioneuroblastoma. Laryngoscope 2008 Nov; 118(11):2006-2010.

10. Loy AH, Reibel JF, Read PW, Thomas CY, Newman SA, Jane JA, et al. Esthesioneuroblastoma: continued follow-up of a single institution's experience. Arch Otolaryngol Head Neck Surg 2006 Feb;13(2):134-138.

\section{ABOUT THE AUTHORS}

\section{Jaimanti Bakshi (Corresponding Author)}

Associate Professor, Department of ENT, Postgraduate Institute of Medical Education and Research, Chandigarh, India, e-mail: drjayabakshi@ymail.com

\section{Anil K Dash}

Senior Research Associate, Department of Otolaryngology and Head and Neck Surgery, Postgraduate Institute of Medical Education and Research, Chandigarh, India

\section{Bhumika Gupta}

Senior Resident, Department of Otolaryngology and Head and Neck Surgery, Postgraduate Institute of Medical Education and Research Chandigarh, India

\section{Naresh K Panda}

Head, Department of Otolaryngology and Head and Neck Surgery Postgraduate Institute of Medical Education and Research Chandigarh, India 